\title{
Use of magnetic resonance cholangiography in the diagnosis of choledocholithiasis: prospective comparison with a reference imaging method
}

\author{
S H Zidi, F Prat, O Le Guen, Y Rondeau, L Rocher, J Fritsch, A D Choury, G Pelletier
}

\begin{abstract}
Background-Magnetic resonance cholangiography (MRC) is a new technique for non-invasive imaging of the biliary tract.

Aim-To assess the results of MRC in patients with suspected bile duct stones as compared with those obtained with reference imaging methods.

Patients/Methods-70 patients (34 men and 36 women, mean (SD) age 71 (15.5) years; median 75) with suspected bile duct stones were included (cholangitis, 33; pancreatitis, three; suspected post-cholecystectomy choledocholithiasis, nine; cholestasis, six; stones suspected on ultrasound or computed tomography scan, 19). MR cholangiograms with two dimensional turbo spin echo sequences were acquired. Endoscopic retrograde cholangiography with or without sphincterotomy $(n=63)$, endosonography $(n=5)$, or intraoperative cholangiography $(n=2)$ were the reference imaging techniques used for the study and were performed within 12 hours of MRC. Radiologists were blinded to the results of endoscopic retrograde cholangiography and previous investigations.
\end{abstract}

Results-49 patients $(70 \%)$ had bile duct stones on reference imaging (common bile duct, 44, six of which impacted in the papilla; intrahepatic, four; cystic duct stump, one). Stone size ranged from 1 to 20 mm (mean 6.1, median 5.5). Twenty seven patients $(55 \%)$ had bile duct stones smaller than $6 \mathrm{~mm}$. MRC diagnostic accuracy for bile duct lithiasis was: sensitivity, $57.1 \%$; specificity, $100 \%$; positive predictive value, $100 \%$; negative predictive value, $50 \%$.

Conclusions-Stones smaller than $6 \mathrm{~mm}$ are still often missed by MRC when standard equipment is used. The general introduction of new technical improvements is needed before this method can be considered reliable for the diagnosis of bile duct stones.

(Gut 1999;44:118-122)

Keywords: bile duct calculi; endoscopic retrograde cholangiography; magnetic resonance cholangiography

Correspondence to: Dr F Prat, Service des Maladies du Foie et de

l'Appareil Digestif, 78 rue du Général Leclerc, Bicêtre Hospital, 94275 Le Kremlin Bicêtre, France.

Accepted for publication 22 July 1998

Endoscopic retrograde cholangiography (ERC), percutaneous transhepatic cholangiography, and intraoperative cholangiography are considered to be the best diagnostic methods for common bile duct (CBD) stones ${ }^{1}$; however, these procedures are invasive. Transcutaneous ultrasonography is generally used for the initial evaluation of patients presenting with symptoms consistent with choledocholithiasis but its diagnostic yield is low. The diagnostic accuracy of endoscopic ultrasonography for biliary tract stone disease is greater than $95 \%$ and compares favourably with ERC. However, the accuracy of both techniques is highly dependent on the operator. ${ }^{12}$ Magnetic resonance cholangiography (MRC) is a non-invasive method of imaging the biliary tract. No contrast medium, sedation, or analgesics are needed. Several reports have shown the ability of MRC to display the biliary tree by combining the advantages of projectional and cross sectional views. ${ }^{3}$ The major challenge for MRC is whether it will reach the diagnostic accuracy of ERC and endosonography for CBD stones and assume a diagnostic role. Our aim was to assess the results of MRC in patients with suspected CBD stones as compared with the standard methods.

\section{Patients and methods}

PATIENT POPULATION

Seventy consecutive inpatients with suspected CBD stones were prospectively included in the study over a period of 12 months. There were 34 men and 36 women, mean (SD) age 71 (15.5) years (median 75, range 30-93). The patients were referred for direct cholangiography (or endosonography) because of cholangitis $(33 ; 47 \%)$, acute pancreatitis (three; $4 \%$ ), suspected post-cholecystectomy choledocholithiasis (nine; 13\%), cholestasis (six; 9\%), and stones suspected from ultrasound or computed tomography scan $(19 ; 27 \%)$.

MAGNETIC RESONANCE CHOLANGIOGRAPHY MRC examination was performed within the 12 hours preceding direct cholangiography on a $1.5 \mathrm{~T}$ unit (Siemens Magnetomvision, Munich, Germany) with a body coil. Patients did not receive antiperistaltic agents but fasted before MRC to reduce motion artefacts from bowel peristalsis. A preliminary MRC survey of the upper abdomen was first performed with heavily T2 weighted gradient echo sequences. MR cholangiograms were acquired using nonbreath-holding fat suppressed respiratory triggered turbo spin echo (TSE) sequences. Two dimensional TSE imaging was performed in
Abbreviations used in this paper: MRC, magnetic resonance cholangiography; ERC, endoscopic retrograde cholangiography; $\mathrm{CBD}$, common bile duct; TSE, turbo spin echo; CT, computed tomography; MRI, magnetic resonance imaging. 
the axial and coronal planes; the latter were not parallel to the hilum. The source images obtained were reformatted into targeted small volume maximum intensity projection images when necessary to clarify the anatomy further. Twenty five oblique coronal source images with a $5 \mathrm{~mm}$ section thickness and no overlap were acquired. The imaging parameters were: repetition time/echo time, 4500 milliseconds/138 milliseconds; matrix, $174 \times 256$; acquisition time, 1 minute 53 seconds for each pile of sections (two or three piles were needed for biliary tree coverage).

The radiologists who performed the MRC were blinded to any radiographic information - that is, sonography and/or computed tomography (CT) scan results. The only information of which they were aware was the suspicion of CBD stones.

REFERENCE IMAGING METHODS

ERC was performed with TJF 100 or TJF 130 duodenoscopes (Olympus, Tokyo, Japan) in 63 patients. All procedures were carried out under general anaesthesia and using antibiotic prophylaxis. Endoscopic sphincterotomy was performed in 55 patients and endoscopic balloon dilatation in four; an instrumental exploration of the CBD with Dormia baskets and retrieval balloon passage through the bile duct was performed in all cases. The presence of CBD stones was confirmed on their removal or they were actually seen passing through the sectioned sphincter into the duodenal lumen. In four patients, the cholangiogram was normal and no endoscopic sphincterotomy was performed. In five patients, the diagnosis of choledocholithiasis was based on endosonography. ${ }^{1}$ Endoscopic ultrasonography was performed under general anaesthesia. The biliary tract was traced from the papilla of Vater up to the hepatic bifurcation. The left intrahepatic bile ducts were also examined. Two patients had intraoperative cholangiography during cholecystectomy.

IMAGE ANALYSIS

The magnification factor was corrected in the determination of CBD calibre on cholangiograms; CBD calibre was considered to be dilated if it was larger than $7 \mathrm{~mm}$, except in patients after a cholecystectomy, in whom a CBD up to $9 \mathrm{~mm}$ in diameter was assumed to be normal. These criteria were also applied for endosonography and MRC measurements of the CBD. MRC and direct cholangiography images were separately interpreted by radiologists and endoscopists in a blinded fashion, and discrepancies among observers were settled by consensus. Both teams evaluated the following items: CBD calibre; level of obstruction if any; number, size, and location of intraluminal signal voids for MRC; number of filling defects and/or stones removed and their sizes and localisation within the CBD for ERC. The presence of gallstones, cystic duct calculi, bile duct strictures, dilated intrahepatic biliary tree, or associated lesions were also examined. The endoscopists were aware of all clinical, bio-
Table 1 Determination of common bile duct (CBD) calibre by magnetic resonance cholangiography (MRC)

\begin{tabular}{lll}
\hline & $\begin{array}{l}\text { Dilated CBD } \\
\text { (reference method) }\end{array}$ & $\begin{array}{l}\text { Undilated CBD } \\
\text { (reference method) }\end{array}$ \\
\hline Dilated CBD (MRC) & 36 & 2 \\
Undilated (MRC) & 10 & 22 \\
Total & $46(66 \%)$ & $24(34 \%)$ \\
\hline
\end{tabular}

chemical, and previous imaging findings except those of MRC.

JUDGMENT CRITERIA AND STATISTICAL ANALYSIS

The main judgment criterion was the information on the presence or absence of CBD stones yielded by MRC. Secondary criteria were: image diagnostic quality; accuracy of CBD assessment; ability to yield useful additional information. Descriptive statistics and rough data were used for the calculation of sensitivity, specificity, and positive and negative predictive values. The aim of the study was to provide a first evaluation of MRC as it is currently used in a university hospital with a conventional commercial magnetic resonance imaging (MRI) system. We considered that a minimal sample size of 50 patients would be sufficient to produce such information.

\section{Results}

IMAGE DIAGNOSTIC QUALITY

MR cholangiograms giving complete delineation of the CBD were obtained in all cases and were technically adequate for interpretation. The quality of the images was considered to be good in 53 cases but only fair in 17 because of slight blurring.

Cholangiograms of diagnostic quality were obtained in all the patients who underwent ERC.

BILE DUCT CALIBRE (TABLE 1)

At ERC, endosonography, or intraoperative cholangiography, the CBD was found to be undilated in 24 patients (34\%) and dilated in $46(66 \%)$. MRC correctly identified normal calibre CBD, common hepatic and intrahepatic bile ducts in 22 cases $(92 \%)$. In the five cases in which endosonography was the sole reference method used, the entire CBD was visualised as being of normal calibre and echo clear. The two patients who underwent intraoperative cholangiography also had a normal CBD. Thirty six patients $(78 \%)$ with dilated CBD were correctly evaluated by MRC with regard to duct calibre. CBD diameter was overestimated by MRC in two patients $(8 \%)$. One of these was found to have a choledochal cyst at ERC. A dilated CBD was interpreted as being normal at MRC in 10 patients (22\%).

\section{CBD STONES}

Forty nine patients $(70 \%)$ had CBD stones; stone size ranged from 1 to $20 \mathrm{~mm}$ (mean 6.1 $\mathrm{mm}$, median $5.5 \mathrm{~mm}$ ). A single stone (fig 1) was found in 17 patients $(35 \%)$ (less than 6 $\mathrm{mm}$ in size in 10 patients and $8-20 \mathrm{~mm}$ in seven), and 32 patients had two or more stones. Twenty seven (55\%) patients had stones smaller than $6 \mathrm{~mm}$. Fourteen patients had 


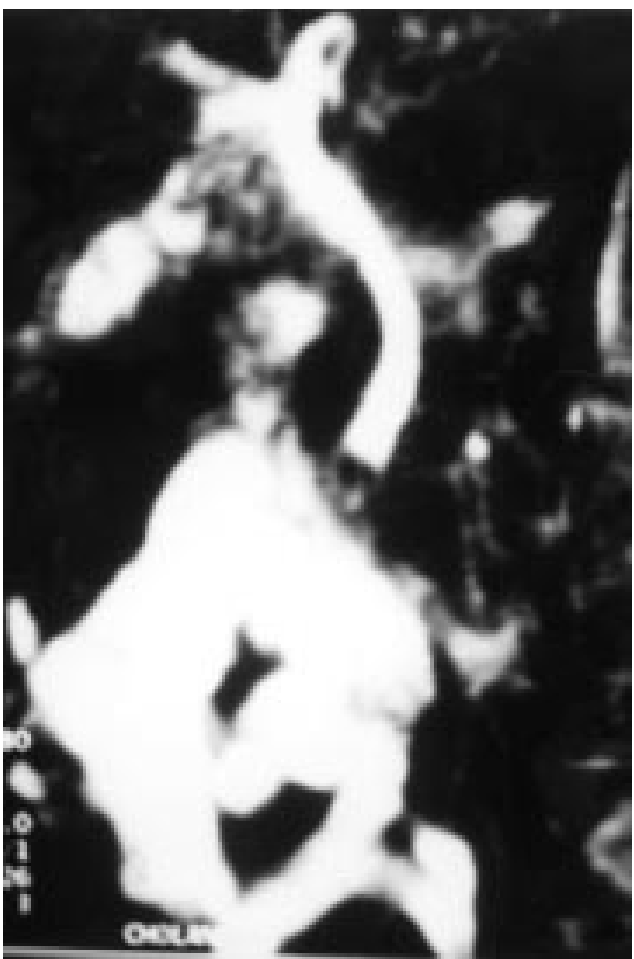

Figure 1 Coronal magnetic resonance cholangiography image showing a single $8 \mathrm{~mm}$ stone within the lower common bile duct. The common bile duct is slightly dilated $(8.5 \mathrm{~mm})$.

Table 2 Comparison of choledocholithiasis diagnosis by magnetic resonance cholangiography $(M R C)$ and reference methods

\begin{tabular}{lll}
\hline & $\begin{array}{l}\text { Stones present } \\
\text { (reference method) }\end{array}$ & $\begin{array}{l}\text { No stones } \\
\text { (reference method) }\end{array}$ \\
\hline Stones (MRC) & 28 & 0 \\
No stones (MRC) & 21 & 21 \\
Total & 49 & 21 (3 non-lithiasis \\
& & obstructions) \\
\hline
\end{tabular}

Table 3 Choledocholithiasis diagnosis in relation to stone size

\begin{tabular}{lll}
\hline Size & $\begin{array}{l}\text { No of cases observed } \\
\text { by reference method }\end{array}$ & $\begin{array}{l}\text { No of cases } \\
\text { observed by MRC }\end{array}$ \\
\hline$\leqslant 6 \mathrm{~mm}$ & $27(55.1)$ & $9 / 27(33.3)$ \\
$>6$ and $\leqslant 10 \mathrm{~mm}$ & $16(32.7)$ & $15 / 16(93.7)$ \\
$>10 \mathrm{~mm}$ & $6(12.2)$ & $4 / 6(66.7)$ \\
Total & $49(100)$ & $28 / 49(57.1)$ \\
\hline
\end{tabular}

Values in parentheses are percentage of cases with lithiasis. In patients with stones of various size, the largest one is taken account of for the table.

MRC, magnetic resonance cholangiography.

Table 4 Stone size in the subgroup of patients with small stones $(\leqslant 6 \mathrm{~mm})$

\begin{tabular}{lll}
\hline Size (mm) & $\begin{array}{l}\text { No of cases observed by } \\
\text { reference method }\end{array}$ & $\begin{array}{l}\text { No of cases observed by } \\
\text { MRC }\end{array}$ \\
\hline $1-2$ & 5 & 1 \\
$1-3$ & 6 & 2 \\
$2-4$ & 6 & 3 \\
$4-6$ & 10 & 3 \\
Total & 27 & 9 \\
\hline
\end{tabular}

Some patients from each size group had two stones or more. MRC, magnetic resonance cholangiography.

more than five stones of smaller size (1-7 mm). Forty four patients $(90 \%)$ had stones located in the CBD (six of which were impacted in the papilla), four had intrahepatic stones, and one had a stone in the cystic duct stump. In the 21 remaining patients, direct cholangiography (or endosonography in five cases) gave negative results for CBD stones; however, nine patients (13\%) had endoscopic stigmata of stone migration (papillary oedema, gaping orifice, sludge in the CBD), and in one patient sphincter of Oddi dysfunction was diagnosed (bile duct dilatation above smooth terminal narrowing and delayed emptying). Two patients were found to have small intrapapillary cholangiocarcinomas and one patient had an external compression of the CBD. These findings were identified as such at MRC and confirmed by ERC. In eight patients ( $11 \%$ ), the final diagnosis remained unclear.

As mentioned above, all MRC images were adequate for interpretation in our study, although the quality of the images was reported as only "fair" in 17 because of slight blurring. Of these 17 cases, eight had calculi on standard examination and four of the eight were detected by MRC (50\%). Stones in the four cases missed by MRC were as follows: a single $3 \mathrm{~mm}$ calculus, numerous 2 to $10 \mathrm{~mm}$ stones and a single $5 \mathrm{~mm}$ calculus of the CBD, and one $10 \mathrm{~mm}$ intrahepatic stone. Stones in the four cases detected by MRC were as follows: a single $4 \mathrm{~mm}$ calculus and two $10 \mathrm{~mm}$ stones in the CBD, and one $10 \mathrm{~mm}$ intrahepatic stone.

CORRELATION OF RESULTS FROM MRC WITH THOSE FROM THE REFERENCE METHOD (TABLE 2) Of the 49 patients with biliary stone disease, 28 cases were identified by MRC and 21 cases of bile duct lithiasis were missed. The diameter of stones detected by MRC ranged from 2 to 20 $\mathrm{mm}$. There were no false positive MRC results, giving $100 \%$ specificity, $57.1 \%$ sensitivity, $100 \%$ positive predictive value, and 50\% negative predictive value.

STONES MISSED AT MRC (TABLES 3 AND 4)

The 21 cases of choledocholithiasis not detected by MRC comprised two patients with a single $4 \mathrm{~mm}$ intrapapillary impacted stone, seven with a single CBD stone $(3-5 \mathrm{~mm}$ in size), three with numerous CBD stones (10-13 $\mathrm{mm}$ in size in two and $2-10 \mathrm{~mm}$ in size in one), seven with two or more stones of less than 6 $\mathrm{mm}$ within the CBD, and two with intrahepatic stones.

STONES MISSED AT MRC CORRELATED WITH CBD CALIBRE AND STONE SIZE (TABLE 5)

Of the 46 patients with a dilated CBD, 39 had CBD stones, and of these 39 patients, 24 $(62 \%)$ were picked up by MRC (table 3$)$. In the seven with a dilated CBD and no stones, MRC and ERC identified two small tumours of the lower CBD and one case of extrinsic compression of the CBD. The median size of stones in dilated CBD missed at MRC (15 cases) was 5 $\mathrm{mm}$. Twenty four patients had a normal CBD calibre and $10(42 \%)$ of these had ductal lithiasis. Stones in undilated CBD were seen at MRC in $4 / 10$ cases $(40 \%)$. The median size of the stones in undilated CBD that were missed at MRC (six cases) was $3 \mathrm{~mm}$. 
Table 5 Choledocholithiasis diagnosis at magnetic resonance cholangiography (MRC) correlated with common bile duct (CBD) calibre

\begin{tabular}{llll}
\hline & $\begin{array}{l}\text { Dilated CBD } \\
\text { (reference method) }\end{array}$ & $\begin{array}{l}\text { Undilated CBD } \\
\text { (reference method) }\end{array}$ & Total \\
\hline Total & 46 & 24 & 70 \\
$\begin{array}{l}\text { Stones (reference method)/stones (MRC) } \\
\text { No stones (reference method)/no stones }\end{array}$ & $39 / 24$ & $10 / 4$ & $49 / 28$ \\
$\quad(M R C)$ & $7 / 22$ & $14 / 20$ & $21 / 42$ \\
\hline
\end{tabular}

\section{Discussion}

Transcutaneous sonography and CT scan are currently advocated for the initial evaluation of patients with symptoms consistent with choledocholithaisis. With a few exceptions, the reported sensitivity for $\mathrm{CBD}$ stone diagnosis does not exceed $50 \%$ whereas specificity is higher than $90 \% .^{4}$ Direct cholangiography is generally still considered to be the ideal method for CBD stone diagnosis, although ERC may miss small stones: endoscopic sphincterotomy involving instrumental exploration is usually required to rule them out, especially in a dilated CBD. In our experience, in 245 consecutive cases of suspected CBD stones, the diagnosis was only confirmed after endoscopic sphincterotomy in $5 \%$ of the cases, whereas $8.5 \%$ of the patients in this series may have undergone endoscopic sphincterotomy unnecessarily. ${ }^{5}$ Success rates for cannulation and endoscopic sphincterotomy vary from 90 to $96 \%{ }^{67}$ or even more in expert hands. Reported associated morbidity and death rates range respectively between 9.8 and $13 \%$ and 2.3 and $4 \% .{ }^{8}$ Thus the risk of sphincterotomy related complications in patients with suspected CBD stones who ultimately are found to have no stones indicates the need for careful patient selection before ERC to prevent unnecessary sphincterotomies. Endoscopic ultrasonography is a minimally invasive procedure with minimal morbidity and mortality. ${ }^{10}$ In the absence of stenosis or previous gastric surgery, the transducer is inserted into the inferior portion of the descending duodenum, then slowly withdrawn up to the duodenal bulb, thus allowing complete examination of the CBD through the wall of the duodenum. Images from the tip of the proximal CBD, the ampulla, the junction of the hepatic and cystic ducts, the distal CBD, and the left hepatic ducts are clearly displayed. The right hepatic ducts and hilum are inconsistently displayed. The diagnostic accuracy of endosonography for biliary tract stone disease is higher than $95 \%{ }^{11}$ and compares favourably with that of ERC. ${ }^{12}$ Endoscopic ultrasonography has been proposed to be the most suitable imaging method for detecting CBD stones before cholecystectomy. ${ }^{2}$

Preliminary early reports indicate that MRC could be used to delineate the anatomy of the biliary tract and depict dilated bile ducts and biliary obstruction. ${ }^{12-14} \mathrm{MRC}$ imaging is based on the use of heavily $\mathrm{T} 2$ weighted sequences to highlight static or slowly flowing fluid which provide high signal intensity whereas the background appears hypointense. Patient cooperation for breath holding techniques was demanded in earlier studies and some patients were excluded because of this constraint. Stud- ies using fast spin echo sequences without breath holding have provided an excellent T2 contrast. Non-breath-holding techniques ${ }^{13}$ 16-19 have been developed, allowing significant improvements in image quality, but the acquisition time of several minutes does not preclude motion (peristaltic or respiratory) artefacts. Diagnostic accuracy for choledocholithiasis and stenoses ranges from 71 to $100 \%{ }^{18}{ }^{19}$ To expand the clinical use of this less invasive diagnostic imaging modality, technical refinements such as the use of fast spin echo variants allowing rapid acquisition within a few seconds (such as RARE or HASTE) have been proposed. ${ }^{315}$ We did not use these rapid acquisition variants as they are not available at present in our unit. We used instead a two dimensional maximum intensity projection image respiratory triggered TSE sequence technique. We did not use a specialised surface receiver coil but a conventional body coil which is generally available in university hospitals in France. In the present study, MRC correctly delineated normal and dilated CBDs in 58 patients $(83 \%)$. This figure is close to other data reported in the literature. ${ }^{18}$

Few reports have specifically addressed the use of MRC for diagnosing gallstone disease. ${ }^{18}$ 20-23 To our knowledge, only five reports have focused on choledocholithiasis, ${ }^{18-21} 23$ and only two were prospective: one included 126 patients with clinically suspected bile duct obstruction, of which 32 were shown to have CBD stones; in the six cases not diagnosed by MRC, the stones were small (2-7 mm: mean $5 \mathrm{~mm}) .{ }^{19}$ The other prospective study of 47 patients with suspected CBD stones confirmed 19 cases: MRC picked up $18(95 \%)$, and one $10 \mathrm{~mm}$ stone was missed. ${ }^{20}$ However, the median stone size in this series was well above that of the present series, often exceeding $10 \mathrm{~mm}$. A preliminary report on MRC at midfield strength $(0.5 \mathrm{~T})$ gives promising results: $12 / 12 \mathrm{CBD}$ stones ranging in size from 5 to $25 \mathrm{~mm}$ were diagnosed, and discrepancy occurred in one case in which ERC failed to disclose a $5 \mathrm{~mm}$ stone. ${ }^{24}$ Elsewhere in the literature, detailed information on size and characteristics of the stones is scarce, and the number of cases is often small. ${ }^{14-1625-27}$ Some small series found high sensitivities with the use of breath holding sequences $^{27}$ or other technical refinements. ${ }^{12} 1921252628$

In our study of patients with a high suspicion of CBD stones, $49(70 \%)$ actually had biliary stone disease, and 28 of these were diagnosed by MRC. The present study showed a $100 \%$ specificity but a much lower sensitivity for choledocholithiasis $(57.1 \%)$ than some of the previously reported series. This may be because half of the patients with gallstones had small stones: indeed, most of the stones (18/21) missed by MRC were less than $6 \mathrm{~mm}$ in size.

Patients in the study were fasting before MRC but did not receive any antiperistaltic agent, thus motion artefacts may have occurred during the acquisition time (almost two minutes); furthermore small stones may be slowly stirred up in the CBD during the acquisition 
period. Similarly, blurring may result from respiratory movements even when triggering techniques are used to compensate. MRC identified $4 / 10$ cases of choledocholithiasis in undilated CBD but failed to pick up 15/39 cases of stones in dilated CBD. Small stones adjacent to the CBD wall with no contrast between stone and parenchyma may not be seen.

Four patients in our study had intrahepatic lithiasis, and in two this was not identified by MRC. The role of MRC in hepatolithiasis remains to be investigated. ${ }^{27}$ In a recent report of 10 patients with hepatolithiasis, all were detected at MRC whereas direct cholangiography and CT could only diagnose 7/10 and 8/10 cases respectively. In addition, MRC delineated the intrahepatic ducts in all cases and picked up 6/7 cases with associated intrahepatic duct stenosis. ${ }^{29}$

Our results do not reflect the ultimate state of the art technique, but rather present the potential of using MRC in a university hospital with standard equipment. A recent report has prospectively compared MRC using a rapid acquisition technique (snapshot MRC) with ERC. MRC sensitivity and specificity for choledocholithiasis were respectively 92.3 and $95.8 \%$ : on- and off-site MRC readings were performed to detect stones in 24 patients, and stones were seen at MRC in 12/13 patients. Stone size ranged from 3 to $30 \mathrm{~mm}$ (mean 9.4 (7.5))..$^{30}$ The clinical role of MRC will depend not only on its diagnostic accuracy but also on its availability and cost effectiveness. Endosonography and ERC are widely available in France; in contrast, there is roughly one MRI unit per 0.5 million inhabitants in France and each deals with a large range of diseases. Clearly, there are limitations for routine MRI use for diagnosing CBD stone disease, particularly for small stones, because of limited spatial resolution.

Optimal patient management needs timely coupling of diagnosis and therapy; MRC is a purely diagnostic technique. Nevertheless, it may give valuable information on patients in whom ERC is not successful. ${ }^{31}$ The sensitivity of MRC is expected to improve, as further technical refinements on current MRI systems are likely, but a wider availability of the machines is required before it can routinely replace diagnostic ERC.

1 Prat F, Amouyal G, Amouyal P, et al. Prospective controlled study of endoscopic ultrasonography and endoscopic study of endoscopic ultrasonography and endoscopic retrograde cholangiography in patients with susp

2 Palazzo L, Girollet PP, Salmeron M, et al. Value of endoscopic ultrasonography in the diagnosis of common endoscopic ultrasonography in the diagnosis of common
bile duct stones: comparison with surgical exploration and bile duct stones: comparison with surgical

3 Reinhold C, Bret PM. Current status of MR cholangiopancreatography. AfR Am f Roentgenol 1996;166:1285-95.

4 Pasanen P, Partanen K, Pikkarainen P, et al. Ultrasonography, CT, and ERCP in the diagnosis of choledochal stones. Acta Radiol 1992;33:53-6.
5 Prat F, Bou Jaoude J, Ink O, et al. Endoscopic sphinctertomy for suspected choledocholithiasis in patients with and without stones. Am $\mathcal{F}$ Gastroenterol 1995;90:727-31.

6 Boyer J. Sphincterotomie endoscopique et lithiase de la voie biliaire principale. Réalités et perspectives. Gastroenterol Clin Biol 1993;17:241-3.

7 Lenriot JP, Le Neel JC, Hay JM, et al. Cholangiopancréatographie retrograde et sphincterotomie endoscopique pour lithiase biliaire. Evaluation prospective en milieu chirurgical. Gastroenterol Clin Biol 1993;17:244-50.

8 Assouline Y, Liguory C, Ink O, et al. Resultats actuels de la sphinctérotomie endoscopique pour lithiase de la voie biliare principale. Gastroenterol Clin Biol 1993;17:251-8.

9 Freeman ML, Nelson DB, Sherman S, et al. Complications of endoscopic biliary sphincterotomy. $N$ Engl f Med 1996; 335:909-18

10 Lightdale CJ. Indications, contraindications and complications of endoscopic ultrasonography. Gastrointest Endosc 1996;43:S15-18.

11 Caletti G, Ferrari A. Endoscopic ultrasonography. Endoscopy 1996;28:156-73.

12 Hall-Crags MA, Allen CM, Owens CM, et al. MR cholangiography: clinical evaluation in 40 cases. Radiology 1993:189:423-7.

13 Outwater E, Miller L, Gordon S, et al. Non invasive 3-d cholangiography with MR imaging. [Abstract] Gastroenterology 1994;106:A374.

14 Ishizaki Y, Wakayama T, Okada Y, et al. Magnetic resonance cholangiography for evaluation of obstructive jaundice. $\mathrm{Am}$ 7 Gastroenterol 1993;88:2072-7.

15 Miyazaki T, Yamashita Y, Tsuchigame T, et al. MR cholangiopancreatography using HASTE ( half-fourier acquisition single-shot turbo spin-echo) sequences. $A f R A m \mathcal{F}$ tion single-shot turbo spin-ech
Roentgenol 1996;166:1297-303.

16 Barish MA, Kent Yucel E, Soto JA, et al. MR cholangiopancreatography: efficacy of three-dimensional turbo spin-echo technique. AfR Am f Roentgenol 1995;165: 295-300.

17 McDermott VG, Nelson RC. Re: MR cholangiopancreatography: efficacy of three-dimensional turbo spin-echo technique. AfR Am f Roentgenol 1995;165: $301-2$.

18 Guibaud L, Bret PM, Reinhold C, et al. Bile duct obstruction and choledocholithiasis: diagnosis with MR cholangiography. Radiology 1995;197:109-15.

19 Macauley SE, Schulte SJ, Sekijima JH, et al. Evaluation of a non-breath-hold MR cholangiography technique. Radiology 1995;196:227-32.

20 Chan Y, Chan ACW, Lam WWM, et al. Choledocholithiasis: comparison of MR cholangiography and endoscopic retrograde cholangiography. Radiology 1996;200:85-9.

21 de Ledinghen V, Lecesne R, Raymond JM, et al. Endoscopic ultrasonography versus magnetic resonance cholangiography for the diagnosis of common bile duct stones: preliminary results of a prospective controlled study. Hepatology [Abstract] 1996;24:172A.

22 Chan FL, Chan JKF, Leong LLY. Modern imaging in the evaluation of hepatolithiasis. Hepatogastroenterology 1997; 44:358-69.

23 Becker CD, Grossholz M, Becker M, et al. Choledocholithiasis and bile duct stenosis: diagnostic accuracy of MR cholangiopancreatography. Radiology 1997;205:523-30.

24 Pavone P, Laghi A, Catalano C, et al. MR cholangiopancreatography (MRCP) at $0.5 \mathrm{~T}$ : technique optimisation and preliminary results. European Radiology 1996;6:147-52.

25 Soto JA, Barish MA, Kent Yucel E, et al. Magnetic resonance cholangiopancreatography: comparison with endoscopic retrograde cholangiography. Gastroenterology 1996;110:589-97.

26 Maccari G, Feliciangeli G, Giovagnoni A, et al. Magnetic resonance cholangiography (MRC) in cholestatic jaundice. Endoscopy 1996;28:S6

27 Dupas B, Le Neel JC, Masliah C, et al. Magnetic resonance cholangiopancreatography, alternative method in bile duct obstruction diagnosis. Endoscopy 1996;28:S7.

28 Macaulay S, Schulte S, Obregon R, et al. Optimized magnetic resonance cholangiography: comparison with endoscopic retrograde cholangiography. Gastroenterology [Abstract] 1994;106:A347.

29 Kubo S, Hamba H, Hirohashi K, et al. Magnetic resonance cholangiography in hepatolithiasis. Am $\mathcal{f}$ Gastroenterol 997;92:629-32.

30 Holzknecht N, Gauger J, Sackmann M, et al. Breath-hold MR cholangiography with snapshot techniques: prospective comparison with endoscopic retrograde cholangiography. Radiology 1998;206:657-64.

31 Soto JA, Kent Yucel E, Barish MA, et al. MR cholangiopancreatography after unsuccessful or incomplete ERCP. Radiology 1996;199:91-8. 